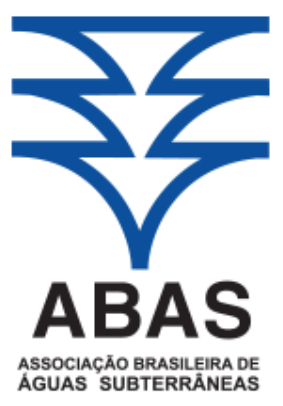

Águas Subterrâneas (2017) 31(3):281-295.

\title{
TIPOLOGIA HIDROGEOQUÍMICA E QUALIDADE DAS ÁGUAS SUBTERRÂNEAS NA ÁREA URBANA DO MUNICÍPIO DE LENÇÓIS, BAHIA, NORDESTE DO BRASIL
}

\author{
HYDROGEOCHEMISTRY TYPOLOGY AND QUALITY OF \\ GROUNDWATER IN THE URBAN AREA OF \\ MUNICIPALITY OF LENÇÓIS, BAHIA, BRAZILIAN \\ NORTHEAST
}

\author{
Jonatas Batista Mattos ${ }^{1}$; Manoel Jerônimo Moreira Cruz ${ }^{1}$; \\ Francisco Carlos Fernandes De Paula ${ }^{2}$; Elinaldo Fonseca Sales ${ }^{1}$
}

Artigo recebido em: 24/03/2017 e Aceito para publicação em: 27/07/2017.

DOI: http://dx.doi.org/10.14295/ras.v31i3.28852

\begin{abstract}
Resumo: Este trabalho teve como objetivo determinar os tipos e a qualidade das águas subterrâneas em aquíferos fissural (metassedimentar) e granular na área urbana do município de Lençóis (Bahia), região Nordeste do Brasil. Para tal, foram levantados quinze poços para amostragem de águas subterrâneas em aquíferos constituídos por rochas quatziticas do Grupo Chapada Diamantina, além de coberturas detríticas. Foram analisados os seguintes parâmetros: condutividade elétrica, temperatura, turbidez, sólidos totais dissolvidos, $\mathrm{pH}$, dureza total, $\mathrm{HCO}_{3}{ }^{-}, \mathrm{Cl}^{-}$, $\mathrm{NO}_{3}^{-}, \mathrm{SO}_{4}^{2-}, \mathrm{PO}_{4}^{3-}, \mathrm{Na}^{+}, \mathrm{K}^{+}, \mathrm{Mg}^{2+}, \mathrm{Ca}^{2+}, \mathrm{Ba}^{2+}$ e $\mathrm{Fe}^{3+}$. Os resultados apontaram que estas águas são de baixa salinidade, ácidas, doces e moles, apresentando uma boa qualidade ambiental para abastecimento e potabilidade. São águas do tipo cloretada sódica, e alguns pontos de uma zona da área urbana indicam traços de contaminação por nitrato, cloreto, sulfato e cálcio, de origem antrópica (águas residuárias). Com base nos diagramas de Gibbs, verificou-se que as águas subterrâneas na área urbana de Lençóis são do domínio da precipitação, evidenciando uma reduzida interação água-rocha. As fontes geogênicas (naturais) dos poucos íons dissolvidos nas águas podem ser atribuídas ao processo de hidrólise que ocorre entre a água e os minerais de quartzo constituintes das rochas da região.
\end{abstract}

Palavras-chave: Hidrogeologia. Recursos hídricos. Chapada Diamantina.

\begin{abstract}
The objective of this paper was to determine the types and quality of groundwater in fractured (metasedimentary) and granular aquifer in the urban area of the municipality of Lençóis, state of Bahia, Northeastern region of Brazil. For this, fifteen groundwater wells for sampling were analyzed in aquifers formed by quartzite rocks of the Chapada Diamantina Group, as well as, detrital cover. These parameters were analyzed: electrical conductivity, temperature, turbidity, total dissolved solids, $\mathrm{pH}$, total hardness, $\mathrm{HCO}_{3}^{-}, \mathrm{Cl}^{-}, \mathrm{NO}_{3}^{-}, \mathrm{SO}_{4}^{2-}$, $\mathrm{PO}_{4}^{3-}, \mathrm{Na}^{+}, \mathrm{K}^{+}, \mathrm{Mg}^{2+}, \mathrm{Ca}^{2+}, \mathrm{Ba}^{2+}$ e $\mathrm{Fe}^{3+}$. The results indicated that these waters are of good environmental quality for supply and potability, furthermore, they are freshwater, acid, soft and with low salinity. They waters are Na$\mathrm{Cl}$, and some points in a zone of the urban area indicate traces of nitrate, chloride, sulfate and calcium contamination, of anthropic source (wastewater). Based on the Gibbs diagrams, found that the groundwater in the urban area of Lençóis is of the rainfall dominance, evidencing a reduced water-rock interaction. The geogenic sources (natural) of the few dissolved ions in the waters can be attributed to hydrolysis process that occurs between the water and the quartz minerals constituent of rocks of the region.
\end{abstract}

Keywords: Hydrogeology. Water resources. Chapada Diamantina.

\footnotetext{
${ }^{1}$ Universidade Federal da Bahia (UFBA), Salvador, BA. E-mails: (jon.geociencia@gmail.com, jeronimo@ufba.br, elinaldo@ufba.br)

2 Universidade Estadual de Santa Cruz (UESC), Ilhéus, BA. E-mail: (eppaula@uesc.br)
} 


\section{INTRODUÇÃO}

Os recursos hídricos subterrâneos, atualmente, assumem um relevante e estratégico papel na proposição de variadas atividades socioeconômicas. Conhecer este recurso fundamental para estas atividades, assim como sua dinâmica no meio ambiente, torna-se necessário para tomada de decisões. Os estudos sobre geoquímica de águas subterrâneas têm buscado responder questões sobre as características e o comportamento das concentrações iônicas naturais presentes na água. As respostas encontradas nestes estudos, podem, de acordo com Vivona et. al. (2007), auxiliar no estabelecimento de medidas, ações preventivas e mitigadoras, capazes de reduzir os riscos de contaminação de uma população que consome determinado recurso hídrico, evitando danos à saúde pública.

A influência de fatores naturais na qualidade das águas subterrâneas é, na maioria das vezes, determinante na definição dos distintos usos da água, primários e/ou secundários (LONG et al, 2009; Conceição et al., 2014). Além destes fatores, há a interferência humana que implica em mudanças das características químicas das águas (CONBOY e GOSS, 2000). Diversos estudos em países dos cinco continentes, apontam que as concentrações de substâncias dissolvidas em águas subterrâneas tendem a aumentar, à medida que percorrem diferentes ambientes hidrogeológicos, além da interferência humana.

Aquíferos subjacentes a áreas antropizadas estão expostos a riscos de contaminação de suas águas, dependendo tanto de fatores geológicos, que caracterizam sua vulnerabilidade, quanto a intensidade das fontes dos contaminantes. Em áreas urbanizadas é comum identificar águas subterrâneas contaminadas, por exemplo, pelo nitrato, a partir de vazamentos nas tubulações de coleta de esgoto, fossas negras ou disposição inadequada de águas residuárias
(SILVA-FILHO et al., 2009; ZHANG et al., 2015). Esta realidade, representa uma grande preocupação, pois, além de oferecer riscos à saúde pública, pode, muitas vezes, inviabilizar a recuperação da qualidade dos sistemas aquíferos.

A exploração das águas subterrâneas na área urbana do município de Lençóis, na Chapada Diamantina, tem sido crescente, a fim de subsidiar sua principal atividade econômica (turismo). Além disso, estas águas representam uma fonte alternativa de abastecimento, já que em períodos de maior estiagem há uma redução significativa da vazão das águas superficiais, alterando desta forma as regras de oferta e demanda de água. Desse modo, além do entendimento sobre a hidrogeologia local, a litologia, o regime hidrológico, a gestão de resíduos sólidos e águas urbanas passam a ser preponderantes para o entendimento da qualidade da água e evolução geoquímica.

Desse modo, o objetivo deste trabalho foi determinar os tipos e a qualidade das águas subterrâneas em aquíferos metassedimentares e granulares na área urbana do município de Lençóis (Bahia), Nordeste do Brasil. Para tal, buscou-se a caracterização hidrogeoquímica e a identificação dos fatores controladores da qualidade destas águas.

\section{2 ÁREA DE ESTUDO}

A área analisada localiza-se na porção central do estado da Bahia, no município de Lençóis, região da Chapada Diamantina, entre as coordenadas geodésicas $12^{\circ} 33^{\prime} 12^{\prime \prime}$; $12^{\circ} 34^{\prime} 27^{\prime \prime} \mathrm{S}$ e $41^{\circ} 23^{\prime} 49^{\prime \prime} ; 4^{\circ} 22^{\prime} 43^{\prime \prime}$ W (figura 1), sendo a sua sede municipal, com uma área de pouco mais de $2 \mathrm{~km}^{2}$. $\mathrm{Na}$ área urbana do município de Lençóis se estabelece uma importante atividade socioeconômica, o turismo, que recebe cerca de 150.000 turistas anualmente, segundo dados da secretaria de turismo de Lençóis. 
Figura 1 - Localização da área urbana de Lençóis, Bahia

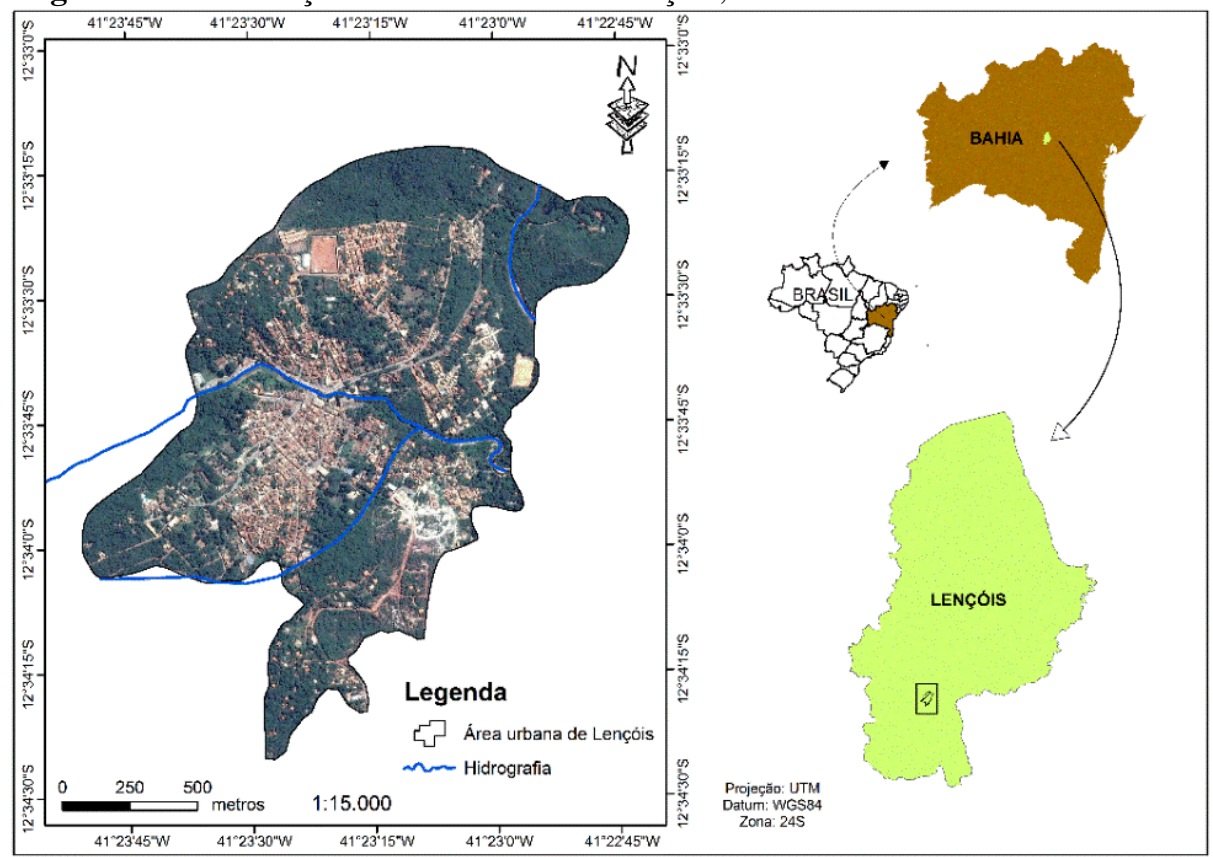

Fonte: IBAMA (2007); Autores (2017)

O clima predominante na área urbana é do tipo cwb (tropical de altitude) na classificação de Koppen (1948), apresentando duas estações bem definidas, com precipitação média anual em torno de 1.107 $\mathrm{mm}$, de acordo com dados de série histórica do INMET (1943-2015). Os registros de valores mínimos anuais são de $800 \mathrm{~mm}$ e máximo, $1.350 \mathrm{~mm}$. Na área urbana e seus entornos, há bosques com espécies de vegetação típicas de caatinga e cerrado (arbustivas), além de alguns fragmentos de mata atlântica, constituindo dessa forma um ambiente de transição entre biomas (MATTOS e DE PAULA, 2017).

O mapa da figura 2 mostra a síntese litológica-hidrogeológica na área urbana de Lençóis. A geologia da área é constituída predominantemente por rochas do Grupo Chapada Diamantina, de origem da Era Mesoproterozoica, com litotipos da Formação
Caboclo (Quartzitos) e da Formação Tombador (Conglomerados, Arenitos Conglomeráticos, Quartzitos). Ocorrem também na porção leste-nordeste da área urbana, coberturas Cenozóicas detrito-lateríticas e depósitos aluvionares recentes (areias, argilas e crostas lateríticas).

O principal domínio hidrogeológico na área urbana de Lençóis é dos metassedimentos, que de acordo com a CPRM (2005), fazem parte da unidade hidrogeológica Chapada Diamantina/Estância/Juá. Este domínio constitui aquíferos mistos (predominantemente fissural com algumas janelas granulares), semiconfinados, com predomínio de porosidade secundária (fendas, fraturas, falhas). Na porção leste-nordeste, o aquífero é granular, livre, de elevada porosidade primária e constituído por formações superficiais Cenozóicas. 
Figura 2 - Mapa de síntese litológica-hidrogeológica da área urbana de Lençóis-BA

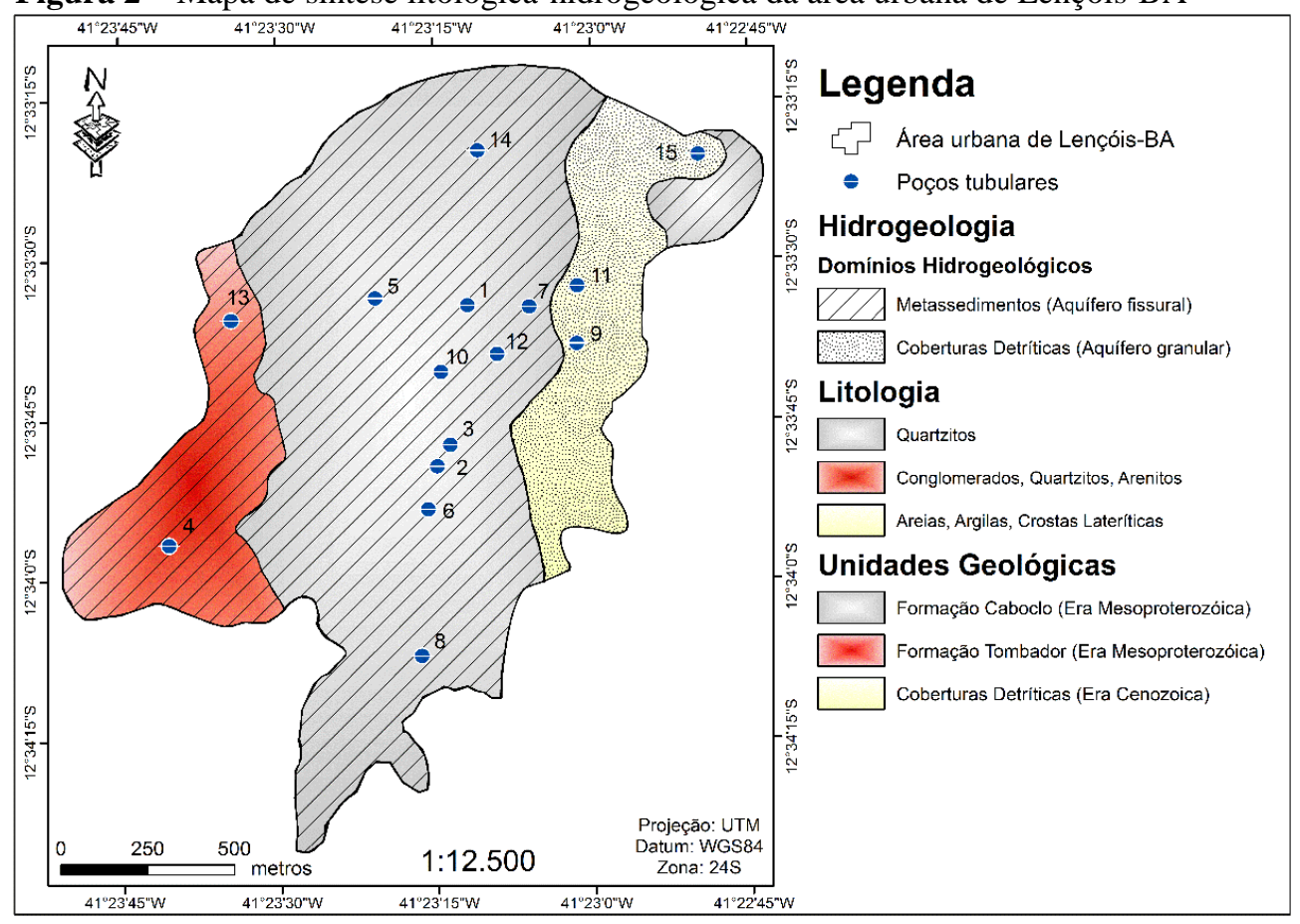

Fonte: Autores (2017); IBAMA (2007)

\section{MATERIAIS E MÉTODOS}

\subsection{Amostragem e preservação das amostras}

A amostragem para este trabalho foi realizada em período de estiagem (Setembro/2015), portanto, um período sem recarga efetiva dos aquíferos. Este período, de acordo com os dados de série histórica do INMET, tabulados pela SEI (1999), é comprovadamente o mais seco. Foram definidos quinze pontos de acordo com a disponibilidade de poços tubulares para coleta de amostras de águas subterrâneas (figura 2), os quais apresentam uma profundidade média de 86,5 metros. Todos os poços são particulares, e a grande maioria são de hotéis ou pousadas que usam as águas subterrâneas para manutenção das suas atividades.

A coleta das amostras foi realizada de acordo com as recomendações dos métodos internacionalmente padronizados pelo Standard Methods for the Examination of Water and Wastewater (APHA, 2012). Todo o material de amostragem foi preparado em etapa pré-campo, onde houve a lavagem e descontaminação dos frascos de polietileno que foram deixados no banho com detergente Extran não fosfatado a 5\% por 24 horas, na sequência foi deixado no $\mathrm{HNO}_{3}$ a $2,5 \%$ e por fim enxaguados com água deionizada.

Os parâmetros físico-químicos medidos em campo foram temperatura, condutividade elétrica, sólidos totais dissolvidos (STD), pH e turbidez, obtidos através da sonda multiparâmetros Horiba ${ }^{\circledR}$ U50, devidamente calibrada. Para determinar a composição aniônica $\left(\mathrm{SO}_{4}^{2-}, \mathrm{NO}_{3}^{-}, \mathrm{PO}_{4}^{3-}, \mathrm{HCO}_{3}^{-}\right.$e $\left.\mathrm{Cl}^{-}\right)$, foram coletadas amostras, cada uma com volume de $1 \mathrm{~L}$. Estas foram filtradas no próprio ponto de amostragem com o uso de bomba manual de vácuo e membrana Milipore $0,45 \mu \mathrm{m}$. Para os metais, cátions $\left(\mathrm{Na}^{+}, \mathrm{K}^{+}\right.$, $\mathrm{Ca}^{2+}, \mathrm{Mg}^{2+}, \mathrm{Fe}^{3+}$ e $\mathrm{Ba}^{2+}$ ) usou-se a mesma frascaria para volume de $1 \mathrm{~L}$ de água e o mesmo tipo de membrana para filtração, preservada em $\mathrm{HNO}_{3}$ concentrado.

As amostras coletadas foram conservadas à baixas temperaturas e acondicionadas em caixas de isopor com gelo e transportados até o Laboratório de Plasma do Instituto de Geociências da UFBA, nesta instituição foram mantidas em refrigeração à $4^{\circ} \mathrm{C}$ até a realização das análises. 


\subsection{Análises Laboratoriais}

Em laboratório, todas as análises realizadas seguiram as orientações técnicas do Standard Methods for the Examination of Water and Wastewater (APHA, 2012). Os ânions nitrato, sulfato e fosfato foram obtidos por espectrofotometria óptica através do espectrofotômetro (HITACHI, modelo U5100). O fosfato foi lido através do método do ácido ascórbico, e para o nitrato e sulfato usou-se os kits de bancada da Hach $^{\circledR}$ (NitraVer5 e Sulfaver4) pelo método de redução de cádmio e pelo método turbidimétrico de sulfato de bário, respectivamente. $\mathrm{O}$ cloreto foi quantificado através do método volumétrico de Mohr, onde os íons cloreto são titulados com solução padronizada de nitrato de prata $\left(\mathrm{AgNO}_{3}\right) \quad 0,01 \mathrm{~N}$, na presença de cromato de potássio $\left(\mathrm{K}_{2} \mathrm{CrO}_{4}\right)$ como indicador (APHA, 2012). A alcalinidade foi obtida pelo método titulométrico, utilizando ácido sulfúrico $\left(\mathrm{H}_{2} \mathrm{SO}_{4}\right) 0,02 \mathrm{~N}$.

Para determinar as concentrações analíticas dos cátions $\mathrm{Na}^{+}, \mathrm{K}^{+}, \mathrm{Mg}^{2+}, \mathrm{Ca}^{2+}$, $\mathrm{Ba}^{2+}$ e $\mathrm{Fe}^{3+}$ usou-se Espectrometria de Emissão Atômica com Plasma Indutivamente Acoplado (ICP-OES) no Laboratório de Estudos do Petróleo - LEPETRO, Núcleo de Estudos Ambientais - NEA, Instituto de Geociências da UFBA. Os limites de determinação foram os seguintes: $0,03 \mathrm{mg} \mathrm{L}^{-1}$ para $\mathrm{Na}^{+}, \mathrm{K}^{+}, \mathrm{Mg}^{2+}, \mathrm{Ca}^{2+}, \mathrm{Ba}^{2+}$ e $\mathrm{Fe}^{3+}$. Para preparação das curvas de calibração foram utilizadas soluções padrões de alta pureza (Merck S.A) para cada elemento com concentração de $100 \mathrm{mg} \mathrm{L}^{-1}$.

\subsection{Análise dos dados, tipos de águas, processos hidrogeoquímicos e SIG}

Para garantir a qualidade analítica dos resultados laboratoriais, foram calculados os erros de balanço iônico para os íons maiores

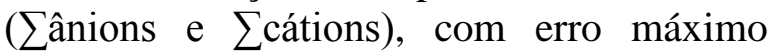
permitido $(\%)$ considerando a condutividade elétrica (CUSTÓDIO \& LLAMAS, 1983). Mais de $70 \%$ das amostras atenderam ao método, estando abaixo dos limites de erro máximo permitido, indicando que os resultados foram representativos em relação aos aquíferos estudados. Os problemas de anormalidade detectados em parte das amostras podem estar associados a subestimação das concentrações iônicas.

Os parâmetros analisados foram submetidos a uma estatística descritiva a fim de revelar o comportamento dos dados, bem como as correlações entre os parâmetros. Tais procedimentos foram executados pelo software Microsoft Excel ${ }^{\circledR}$ (2016) com a extensão Action Stat ${ }^{\circledR}$ (Estatcamp e DIGUP, 2016). Para classificação das águas pelos íons dominantes usou-se o diagrama de Piper (1944) através do software RockWorks ${ }^{\circledR}$ versão 16 (RockWare Inc., 2015). Para classificar a qualidade das águas subterrâneas para potabilidade e abastecimento usou-se a Resolução CONAMA 396/2008 e Portaria MS 2914/2011.

A salinidade foi determinada pelo Qualigraf ${ }^{\circledR} 14$ (Mobus, 2014) que usa como referência a Resolução CONAMA 357/2005. A evolução geoquímica e as características hidrogeoquímicas das águas foram interpretadas por modelagem (índice de saturação e especiação), realizada no software Phreeqc (Parkrusrt e Appelo, 1999) e pelos diagramas de Gibbs (1970), baseados nas razões $\mathrm{Na}^{+} /\left(\mathrm{Na}^{+}+\mathrm{Ca}^{2+}\right)$ e $\mathrm{Cl}^{-} /\left(\mathrm{Cl}^{-}+\mathrm{HCO}^{-}\right)$.

De forma a complementar as informações obtidas pelos resultados analíticos de cada amostra, usou-se, o SIG ArcGis ${ }^{\circledR} 10$ (ESRI Inc., 2010) para execução do geoprocessamento (análises espaciais). O método escolhido para estas análises foi o interpolador IDW (Inverse Distance Weighted) que é um algoritmo que estima um valor para um local não amostrado como uma média dos valores dos dados da vizinhança.

\section{RESULTADOS}

\subsection{Características fundamentais das águas subterrâneas}

A tabela 1 mostra os resultados de alguns parâmetros físicos e químicos das águas subterrâneas na área urbana de Lençóis. A mediana dos valores de condutividade 
elétrica foi $38 \mu \mathrm{S} \mathrm{cm}^{-1}$, sendo o ponto $\mathrm{P} 9$, o de menor valor $\left(22,5 \mu \mathrm{S} \mathrm{cm}^{-1}\right)$ e o ponto $\mathrm{P} 3$, o de maior valor $\left(274 \mu \mathrm{S} \mathrm{cm}^{-1}\right)$. Notavelmente, são águas de baixa salinidade, sendo que, a provável razão da oscilação observada não está relacionada com fatores geogênicos (interação água-rocha), e sim, com fatores antropogênicos. A mediana observada para a temperatura foi $26,4^{\circ} \mathrm{C}$, oscilando entre $25,4^{\circ}$ e $29^{\circ}$.

\begin{tabular}{lcllcl}
\multicolumn{6}{c}{ Tabela 1 - Resultados analíticos dos parâmetros físicos e químicos } \\
\hline Poços & $\begin{array}{c}\mathbf{C E} \\
\left(\boldsymbol{\mu} \mathbf{S ~ c m}^{-1}\right)\end{array}$ & $\begin{array}{l}\text { Temp. } \\
\left({ }^{\mathbf{0}} \mathbf{C}\right)\end{array}$ & $\mathbf{p H}$ & $\begin{array}{c}\text { STD } \\
\left(\mathbf{m g ~ L}^{-\mathbf{1}}\right)\end{array}$ & $\begin{array}{l}\text { Turbidez } \\
(\mathbf{N T U})\end{array}$ \\
\hline P1 & 44 & 25,6 & 4,5 & 29 & 0 \\
P2 & 151 & 26 & 4,9 & 170 & 14,1 \\
P3 & 274 & 26 & 5,2 & 205 & 17,5 \\
P4 & 32 & 29 & 4,9 & 21 & 0 \\
P5 & 83 & 27,4 & 4,2 & 54 & 0 \\
P6 & 170 & 27 & 4,9 & 111 & 3 \\
P7 & 29 & 26,5 & 4,8 & 19 & 159 \\
P8 & 25 & 27 & 5,2 & 16 & 0,2 \\
P9 & 22,5 & 26 & 5,2 & 18 & 0 \\
P10 & 44 & 25,7 & 5,4 & 29 & 0 \\
P11 & 24 & 25,4 & 5,1 & 16 & 0 \\
P12 & 34 & 25,8 & 5 & 22 & 0,3 \\
P13 & 24 & 26,3 & 4,8 & 15 & 0 \\
P14 & 49 & 25,9 & 5,1 & 33 & 403 \\
P15 & 38 & 28,3 & 5 & 25 & 0 \\
\hline Mediana & 38 & 26 & 5 & 25 & 0 \\
\hline
\end{tabular}

$\mathrm{O}$ valor mediano do $\mathrm{pH}$ encontrado para as águas subterrâneas na área urbana de Lençóis foi 5, sendo o menor valor registrado no ponto P5 $(4,2)$, e o maior valor registrado no ponto P10 $(5,4)$. Estas águas apresentam um perfil de acidez, estando todos os pontos analisados, em desconformidade com a recomendação da Portaria 2914/2011 do Ministério da Saúde, que define para o $\mathrm{pH}$ valores entre 6 e 9 como aceitáveis para consumo. Estes resultados indicam que, as rochas e os solos que fazem parte dos processos de interação com a água, são, provavelmente, constituídos por materiais que produzem ácidos inorgânicos e orgânicos, que podem gerar esta acidez observada.

O parâmetro STD, medido através da sonda multiparâmetros, apresentou um valor mediano de $25 \mathrm{mg} \mathrm{L}^{-1}$, sendo o menor valor encontrado no ponto P13 (15 $\left.\mathrm{mg} \mathrm{L}^{-1}\right)$ e o maior no ponto P3 (205 mg L $\left.\mathrm{m}^{-1}\right)$. A turbidez, que representa a quantidade de material em suspensão, é predominantemente baixa, com algumas exceções observadas nos pontos $\mathrm{P} 2$, P3, P7 e P14. As causas de maior turbidez nos pontos acima citados estão relacionadas a falhas de engenharia na construção dos poços, que contém revestimentos insuficientes e inadequados, que provocam a presença de partículas em suspensão.

$\mathrm{Na}$ tabela 2 constam os resultados analíticos da composição aniônica das águas subterrâneas na área urbana de Lençóis. Notase que, a alcalinidade é baixa, com valor mediano de $1,25 \mathrm{mg} \mathrm{L}^{-1}$, estando o maior valor associado ao ponto $\mathrm{P} 3\left(13,1 \mathrm{mg} \mathrm{L}^{-1}\right)$. Estes resultados sugerem a baixa influência do intemperismo químico nestas águas. No ponto $\mathrm{P} 3$, os traços de alcalinidade na água podem estar relacionados a fontes antrópicas (águas residuárias). A mediana observada para o fosfato foi baixa $\left(0,07 \mathrm{mg} \mathrm{L}^{-1}\right)$, sendo o maior valor evidenciado no ponto $\mathrm{P} 3\left(0,7 \mathrm{mg} \mathrm{L}^{-1}\right)$.

A mediana observada para o ânion cloreto foi $6,4 \mathrm{mg} \mathrm{L}^{-1}$, sendo o menor valor registrado no ponto $\mathrm{P} 1\left(2,7 \mathrm{mg} \mathrm{L}^{-1}\right)$ e o maior no ponto $\mathrm{P} 3\left(37,6 \mathrm{mg} \mathrm{L}^{-1}\right)$. Estes valores são consideravelmente baixos, sendo que, nenhuma das amostras ultrapassa o VMP da Portaria 2914/2011 do Ministério da Saúde que determina $250 \mathrm{mg} \mathrm{L}^{-1}$ para o cloreto. Como é possível notar na tabela 2 , os pontos 
Tipologia hidrogeoquímica e qualidade das águas subterrâneas na área urbana do município de Lençóis, Bahia, nordeste do Brasil

P2, P3 e P6 apresentam valores anômalos aos uma zona com águas contaminadas na área demais pontos e representam espacialmente urbana, conforme ilustra o mapa da figura 3(a)

Tabela 2 - Resultados analíticos com as concentrações dos ânions

\begin{tabular}{llllll}
\hline Poços & $\mathbf{H C O}^{-}$ & $\mathbf{P O}_{4}^{\mathbf{3}}$ & $\mathbf{S O}_{4}^{\mathbf{2}}$ & $\mathbf{C l}^{-}$ & NO $^{-}$ \\
\cline { 2 - 6 } & $\left.\mathbf{( m g ~ L}^{-\mathbf{1}}\right)$ & & & & \\
\hline P1 & $<1,0$ & 0,08 & $<1,0$ & 2,7 & 3,8 \\
P2 & 1,9 & 0,22 & 10 & 29,1 & 6,1 \\
P3 & 13,1 & 0,70 & 21 & 37,6 & 15,8 \\
P4 & 1,9 & 0,07 & $<1,0$ & 5,6 & $<0,1$ \\
P5 & $<1,0$ & 0,06 & $<1,0$ & 10,5 & 7,9 \\
P6 & 1,3 & 0,03 & 10,8 & 36,9 & 4,3 \\
P7 & $<1,0$ & 0,06 & $<1,0$ & 5,6 & $<0,1$ \\
P8 & 1,9 & 0,06 & $<1,0$ & 4,2 & $<0,1$ \\
P9 & 2,5 & 0,18 & 1,3 & 5,1 & $<0,1$ \\
P10 & 3,8 & 0,19 & $<1,0$ & 7,6 & 3,6 \\
P11 & 1,3 & 0,03 & $<1,0$ & 5,5 & $<0,1$ \\
P12 & $<1,0$ & 0,02 & $<1,0$ & 7,5 & 3,6 \\
P13 & $<1,0$ & 0,10 & $<1,0$ & 6,4 & $<0,1$ \\
P14 & $<1,0$ & 0,09 & 1,7 & 5,1 & 1,9 \\
P15 & $<1,0$ & $<0,01$ & $<1,0$ & 10,9 & 0,4 \\
\hline Mediana & 1,25 & 0,07 & $<1,0$ & 6,4 & 1,9 \\
\hline
\end{tabular}

Figura 3 - (a) Mapa da distribuição de cloreto nas águas subterrâneas; (b) Mapa da distribuição de sulfato nas águas subterrâneas; (c) Mapa da distribuição de nitrato nas águas subterrâneas; (d) Mapa da distribuição de ferro nas águas subterrâneas

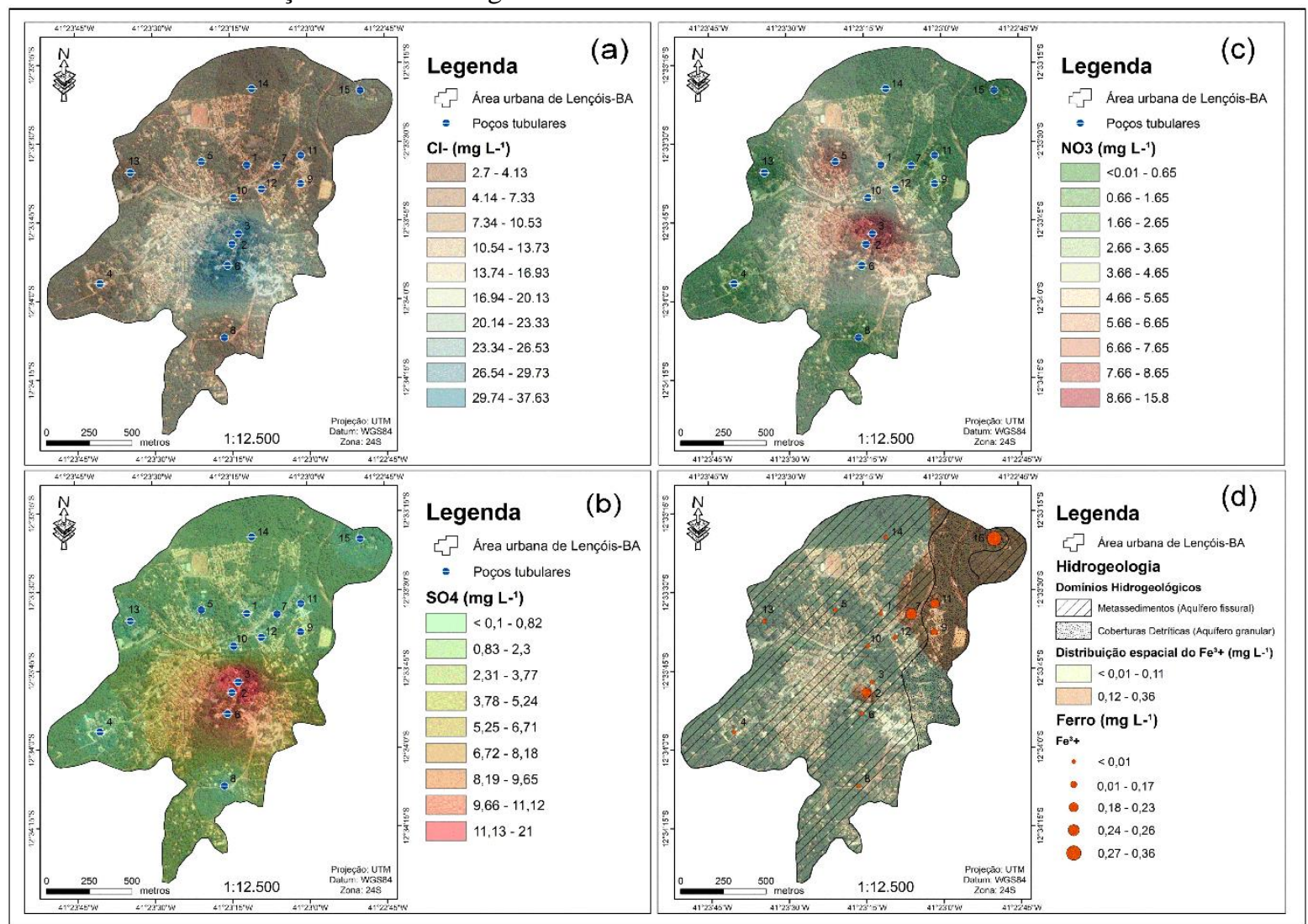

Fonte: Autores (2017) 
O sulfato, nas águas subterrâneas do município de Lençóis é o ânion predominante em um período chuvoso, conforme aborda Mattos et al. (2016) ao observar em algumas localidades, concentrações maiores que 250 $\mathrm{mg} \mathrm{L}^{-1}$ para este ânion. Por outro lado, os resultados do presente estudo mostram que no período de baixa precipitação e recarga dos aquíferos, os valores observados nos aquíferos da área urbana, apresentaram valores inferiores, com um valor de mediana abaixo do limite de quantificação do método, sendo o ponto $\mathrm{P} 3$, a maior concentração observada (21 $\left.\mathrm{mg} \mathrm{L}^{-1}\right)$. A provável origem do sulfato no ponto P3 é antropogênica e junto com os pontos P2 e P6 representam espacialmente uma zona com águas contaminadas na área urbana, como é possível observar no mapa da figura 3(b). Nenhum dos pontos no período analisado extrapolou os limites dos valores máximos permitidos (VMP) pela Portaria 2914/2011 do Ministério da Saúde, sendo o limite de $250 \mathrm{mg} \mathrm{L}^{-1}$ para o ânion sulfato.

O nitrato, é um ânion comumente encontrado em águas subterrâneas de áreas antropizadas, como ilustra os estudos de Murgulet e Tick (2013), Matiatos (2016) e Selvakumar et al. (2017), ao associar a ocorrência deste ânion a urbanização e agricultura, sendo estas, fontes potenciais de contaminação destas águas. Silva e Araújo (2003), Conceição et al. (2014) e Oliveira et al. (2015), encontram valores altos de nitrato em áreas urbanas, e concluem que a origem deste íon está ligada a disposição inadequada de resíduos e gestão ineficiente de águas residuárias, podendo causar danos à saúde da população que consome este recurso hídrico.

$\mathrm{Na}$ área urbana do município de Lençóis, as águas subterrâneas apresentaram um valor mediano de $1,9 \mathrm{mg} \mathrm{L}^{-1}$ para nitrato. A concentração observada no ponto $\mathrm{P} 3$ é a única que ultrapassa o VMP da Portaria 2914/2011 do Ministério da Saúde, que determina $10 \mathrm{mg} \mathrm{L}^{-1}$ para o nitrato. A CETESB (2005) considera o valor $5 \mathrm{mg} \mathrm{L}^{-1}$ para nitrato como base para alertas. Neste cenário, além do ponto $\mathrm{P} 3$, os pontos $\mathrm{P} 2$ e $\mathrm{P} 5$ se enquadram nesta orientação, fazendo-se necessário, o monitoramento anual pela vigilância sanitária do município.

A figura 3(c) ilustra através de um mapa, que os pontos P2, P3 e P6, também estão espacialmente associados a uma zona de águas contaminadas por nitrato, assim como, por sulfato e cloreto, reiterando a hipótese de contaminação por fontes antropogênicas. Nota-se que, o ponto P5, também apresenta um valor anômalo de nitrato $\left(7,9 \mathrm{mg} \mathrm{L}^{-1}\right)$, entretanto, a origem pode estar associada a fatores naturais (decomposição de matéria orgânica), pois, diferentemente dos pontos $\mathrm{P} 2$, P3 e P6, não há indícios de contaminação deste ponto por cloretos e sulfatos (tabela 2). Espacialmente também não há relação estabelecida do ponto P5 com os pontos P2, P3 e P6, como é possível observar no mapa da figura 3(c).

A tabela 3 mostra os resultados analíticos dos constituintes catiônicos das águas subterrâneas na área urbana do município de Lençóis. As concentrações de sódio nas amostras analisadas são baixas, apresentando uma mediana de $0,9 \mathrm{mg} \mathrm{L}^{-1}$, estando a menor concentração associada ao ponto $\mathrm{P} 9\left(0,23 \mathrm{mg} \mathrm{L}^{-1}\right)$ e a maior concentração associada ao ponto $\mathrm{P} 2\left(7,17 \mathrm{mg} \mathrm{L}^{-1}\right)$. Para este parâmetro, nenhum dos pontos analisados ultrapassou os limites estabelecidos pela Portaria 2914/2011 do Ministério da Saúde, $200 \mathrm{mg} \mathrm{L}^{-1}$. O potássio, que, na maioria dos casos, associa-se ao sódio, também apresentou baixas concentrações nas águas subterrâneas da área urbana de Lençóis, com um valor mediano de $0,5 \mathrm{mg} \mathrm{L}^{-1}$.

A presença do cálcio em altas concentrações nas águas subterrâneas depende circunstancialmente da tipologia litológica dos aquíferos, sendo este cátion, associado aos processos de dissolução do mineral calcita em rochas carbonáticas (aquífero cárstico). Sendo assim, os aquíferos da área urbana de Lençóis, predo-minantemente quartzíticos, apresentam baixas concentrações do cálcio em suas águas, com um valor mediano de $0,4 \mathrm{mg} \mathrm{L}^{-1}$. Como é possível observar na tabela 3 , os pontos $\mathrm{P} 2, \mathrm{P} 3$ e P6, apresentaram as maiores concentrações de cálcio $\left(1,15 ; 2,1 ; 0,61 \mathrm{mg} \mathrm{L}^{-1}\right)$, indicando que, a possível fonte destas maiores concentrações é antropogênica. O magnésio, 
que apresenta um comportamento geoquímico similar ao cálcio, também esteve em baixas concentrações, com uma mediana de $0,14 \mathrm{mg}$ $\mathrm{L}^{-1}$. Estes resultados, reiteram a condição de baixa salinidade e boa qualidade em relação a
Resolução CONAMA 357/2005 e Portaria MS 2914/2011 das águas subterrâneas da área urbana de Lençóis, mesmo considerando focos de fontes antropogênicas, em algumas zonas.

Tabela 3 - Resultados analíticos com as concentrações dos cátions

\begin{tabular}{|c|c|c|c|c|c|c|}
\hline \multirow[t]{2}{*}{ Poços } & $\mathrm{Na}^{+}$ & $\mathbf{K}^{+}$ & $\mathrm{Ca}^{2+}$ & $\mathrm{Mg}^{2+}$ & $\mathbf{F e}^{3+}$ & $\mathbf{B a}^{2+}$ \\
\hline & \multicolumn{6}{|l|}{$\left(\mathrm{mg} \mathrm{L}^{-1}\right)$} \\
\hline P1 & 0,75 & 0,29 & 0,50 & 0,15 & $<0,03$ & $<0,03$ \\
\hline P2 & 7,17 & 1,90 & 1,15 & 0,50 & 0,23 & $<0,03$ \\
\hline P3 & 4,44 & 2,72 & 2,10 & 0,66 & $<0,03$ & $<0,03$ \\
\hline P4 & 0,93 & 0,21 & 0,42 & 0,24 & $<0,03$ & $<0,03$ \\
\hline P5 & 1,16 & 0,32 & 0,55 & 0,10 & $<0,03$ & $<0,03$ \\
\hline P6 & 3,10 & 0,64 & 0,61 & 0,21 & $<0,03$ & $<0,03$ \\
\hline P7 & 0,67 & 0,37 & 0,50 & 0,14 & 0,26 & $<0,03$ \\
\hline P8 & 0,32 & 0,40 & 0,20 & 0,10 & $<0,03$ & $<0,03$ \\
\hline P9 & 0,23 & 0,25 & 0,10 & $<0,03$ & 0,17 & $<0,03$ \\
\hline P10 & 0,60 & 0,60 & 0,37 & 0,12 & $<0,03$ & $<0,03$ \\
\hline P11 & 0,68 & 0,54 & 0,34 & 0,10 & 0,22 & $<0,03$ \\
\hline P12 & 0,57 & 0,36 & 0,28 & $<0,03$ & $<0,03$ & $<0,03$ \\
\hline P13 & 1,70 & 1,20 & 0,13 & 0,13 & $<0,03$ & $<0,03$ \\
\hline P14 & 3,60 & 1,12 & $<0,03$ & 0,73 & $<0,03$ & $<0,03$ \\
\hline P15 & 2,32 & 0,85 & $<0,03$ & 0,33 & 0,36 & $<0,03$ \\
\hline Mediana & 0,9 & 0,5 & 0,4 & 0,14 & $<0,03$ & $<0,03$ \\
\hline
\end{tabular}

O cátion bário nas águas subterrâneas da área urbana de Lençóis esteve abaixo dos limites de quantificação do método. $\mathrm{O}$ ferro, por sua vez, apresentou um valor mediano abaixo do limite de quantificação do método, sendo o ponto de maior concentração o P15 $\left(0,36 \mathrm{mg} \mathrm{L}^{-1}\right)$. Este valor foge ligeiramente do padrão estabelecido pela Portaria 2914/2011 do Ministério da Saúde que determina um vmp de $0,3 \mathrm{mg} \mathrm{L}^{-1}$ para o ferro. Somente 5 pontos apresentaram valores significativos de ferro dissolvido nas águas subterrâneas $(\mathrm{P} 2$, P7, P9, P11 e P15). O mapa da figura 3(d) espacializa as concentrações do cátion ferro $\left(\mathrm{Fe}^{3+}\right)$ nas águas subterrâneas da área urbana de Lençóis.

Os poços P9, P11 e P15, apresentam águas de coberturas detríticas (aquífero granular), que apresentam maiores teores de ferro. Estas coberturas em Lençóis, de acordo com a CPRM (2005), são constituídas por sedimentos de naturezas diversas, como areias, argilas, cascalhos e crostas lateríticas, estas últimas, sendo as prováveis origens do cátion $\mathrm{Fe}^{3+}$ observado nas águas subterrâneas dos pontos P9, P11 e P15. A causa da presença de ferro em maiores concentrações nas águas dos pontos P2 e P7 pode estar ligada a oxidação dos revestimentos e filtros dos poços, que são constituídos por ferro nestes dois pontos.

\subsection{Tipos e qualidade das águas subterrâ- neas}

Os tipos de água subterrânea na área urbana de Lençóis, foram quimicamente definidos pelo diagrama de Piper (1944), como ilustra a figura 4. Este diagrama, que calcula as porcentagens de cátions e ânions $\left(\mathrm{mEq} \mathrm{L}^{-1}\right)$, apontou que todas as amostras são do tipo cloretada sódica. Esta tipologia, reforça a hipótese de baixa influência do intemperismo químico das rochas sobre as águas subterrâneas na área urbana de Lençóis. Nascimento et al. (2015), em estudo hidrogeológico realizado no estado da Bahia, associa a origem das águas subterrâneas do tipo cloretada sódica, a águas meteóricas (precipitação). Notavelmente, as águas subterrâneas na área urbana de Lençóis, são fortemente influenciadas pela maior atividade iônica do ânion cloreto, que também estão em maiores concentrações comparado aos demais íons. 
Figura 4 - Diagrama de Piper com a classificação das águas subterrâneas na área urbana de Lençóis, Bahia

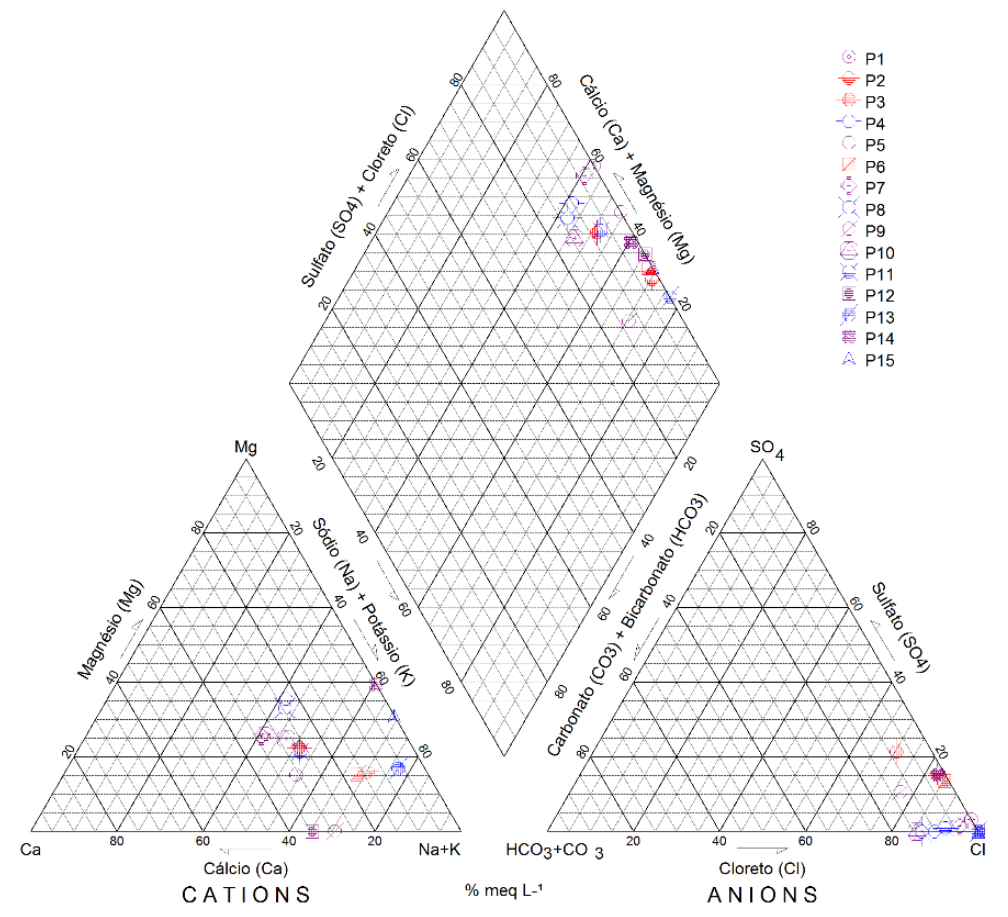

Fonte: RockWare Inc.(2015)

Com os valores de STD, todas as amostras de águas subterrâneas da área urbana de Lençóis foram definidas como doces, tomando por base a orientação da Resolução CONAMA 357/2005 (BRASIL, 2005) que estabelece o intervalo entre 0 e $500 \mathrm{mg} \mathrm{L}^{-1}$ para águas doces. De acordo com esta resolução, que dispõe de uma classificação específica para salinidade das águas, na área urbana do município de Lençóis, as águas subterrâneas definidas como doces, estão aptas para, consumo humano, dessedentação de animais, irrigação de hortaliças e frutas, proteção das comunidades aquáticas e recreação de contato primário.

A Resolução CONAMA 396/2008 (BRASIL, 2008), dispõe de uma classificação específica para águas subterrâneas, definindo seis classes distintas (Especial, I, II, III, IV e $\mathrm{V})$, que considera o valor de referência de qualidade, o VMP para cada elemento mensurado no corpo hídrico e a concentração dos teores iônicos dissolvidos nas águas. Tomando por base esta resolução, as águas subterrâneas na área urbana de Lençóis, no período analisado, são das classes: Especial (P4, P8, P11, P13, P15), I (P1, P5, P7, P9, P10, $\mathrm{P} 12, \mathrm{P} 14)$ e III (P2, P3, P6). A dureza é um parâmetro baseado nas concentrações de cálcio e magnésio na água, podendo ser temporária ou permanente, sendo que, a soma das duas, resulta na dureza total de $\mathrm{CaCO}_{3}$. As águas subterrâneas na área urbana de Lençóis apresentaram um valor mediano de $1,8 \mathrm{mg} \mathrm{L}^{-}$ ${ }_{1}^{1}$ para dureza de $\mathrm{CaCO}_{3}$, sendo, de acordo com Custodio e Llamas (1983) e Sawyer et al. (2000), brandas ou moles. Todas as amostras estão abaixo do VMP estabelecido pela Portaria 2914/2011 do Ministério da Saúde, para dureza total, que é de $500 \mathrm{mg} \mathrm{L}^{-1}$.

\subsection{Fatores controladores da hidro- geoquímica e qualidade das águas}

A hidrogeoquímica das águas subterrâneas na área urbana de Lençóis está predominantemente controlada pelo fator precipitação, como é possível visualizar no diagrama de Gibbs (figura 5). Para determinar este fator, usou-se os diagramas de Gibbs (1970), em que a razão dos ânions $\mathrm{Cl}^{-} /\left(\mathrm{Cl}^{-}+\mathrm{HCO}_{3}^{-}\right)$e dos cátions $\mathrm{Na}^{+} /\left(\mathrm{Na}^{+}+\mathrm{Ca}^{2+}\right)$ são correlacionados com STD. É possível notar que alguns pontos foram plotados fora do boomerang no diagrama. De acordo com Selvakumar et al. (2017), este comportamento pode estar 
associado a fatores antrópicos.

A partir das informações do Diagrama de Gibbs, Nguyen et al. (2015), conseguiram realizar importantes interpretações hidrogeoquímicas, tomando como base a identificação dos fatores governantes das águas de um aquífero livre no Delta do Rio Vermelho
(Vietnam). Em outro contexto metodológico, Gomes et al. (2013), em estudo desenvolvido em aquíferos sedimentares na região de Itaboraí (RJ), encontrou águas subterrâneas com características de águas de precipitação, com reduzidos teores de cloreto.

Figura 5 - Diagrama de Gibbs com as águas subterrâneas na área urbana de Lençóis

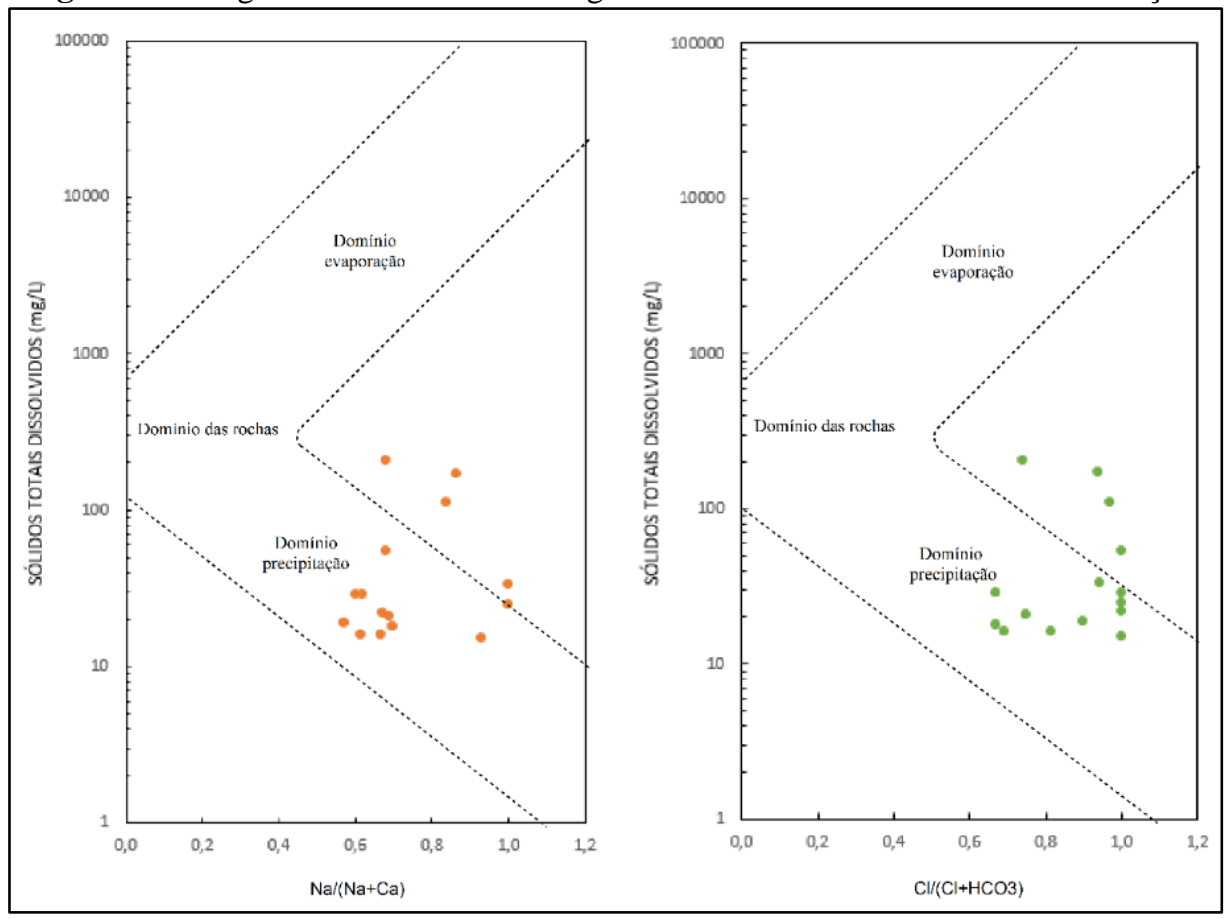

Os aquíferos na área urbana do presente estudo são quartzíticos, que pouco se alteram frente ao intemperismo químico, minimizando dessa forma, os processos de interação água-rocha, e resguardando características das águas de domínios da precipitação (baixa concentração de sais dissolvidos). Estas características indicam que processos como carbonatação e dissolução mineral são descartados como fatores controladores da hidrogeoquímica das águas subterrâneas na área urbana de Lençóis.

Para confirmar as hipóteses e melhor elucidar os fatores controladores da hidrogeoquímica e qualidade das águas, testes estatísticos de correlação foram realizados. A tabela 4, mostra a matriz com os coeficientes de correlação de Pearson para os parâmetros analisados, com exceção do bário, que apresentou valores analíticos abaixo do limite de quantificação do método. Houve correlações significativas entre a condutividade elétrica com quase todos os íons, com exceção do ferro e magnésio.

Destacam-se, as correlações da condutividade elétrica com os ânions sulfato $(\mathrm{r}=0,97)$, cloreto $(\mathrm{r}=0,94)$ e nitrato $(\mathrm{r}=0,88)$ e o cátion cálcio $(0,9)$, indicando a maior influência destes íons no controle da condutividade elétrica das águas subterrâneas na área urbana de Lençóis. 
Tabela 4 - Coeficiente de correlação de Pearson dos parâmetros analisados

\begin{tabular}{lccccccccccc}
\hline & $\mathbf{C E}$ & $\mathbf{p H}$ & $\mathbf{H C O}_{3}{ }^{-}$ & $\mathbf{S O}_{4}^{2-}$ & $\mathbf{C l}$ & $\mathbf{N O}_{3}{ }^{-}$ & $\mathbf{P O}_{4}^{3-}$ & $\mathbf{N a}^{2+}$ & $\mathbf{K}^{+}$ & $\mathbf{C a}^{2+}$ & $\mathbf{M g}^{2+}$ \\
\hline $\mathbf{p H}$ & 0,03 & & & & & & & & & & \\
$\mathbf{H C O}{ }^{-}$ & 0,74 & 0,44 & & & & & & & & & \\
$\mathbf{S O}_{4}^{2-}$ & 0,97 & 0,19 & 0,80 & & & & & & & & \\
$\mathbf{C l}^{-}$ & 0,94 & 0,07 & 0,59 & 0,93 & & & & & & & \\
$\mathbf{N O}_{3}{ }^{-}$ & 0,88 & $-0,11$ & 0,74 & 0,81 & 0,72 & & & & & & \\
$\mathbf{P O}_{4}^{3-}$ & 0,76 & 0,31 & 0,95 & 0,81 & 0,58 & 0,79 & & & & & \\
$\mathbf{N a}^{2+}$ & 0,71 & 0,03 & 0,33 & 0,72 & 0,74 & 0,52 & 0,45 & & & & \\
$\mathbf{K}^{+}$ & 0,78 & 0,24 & 0,71 & 0,82 & 0,70 & 0,69 & 0,80 & 0,82 & & & \\
$\mathbf{C a}^{2+}$ & 0,90 & 0,01 & 0,82 & 0,89 & 0,77 & 0,88 & 0,85 & 0,58 & 0,75 & & \\
$\mathbf{M g}^{2+}$ & 0,59 & 0,18 & 0,45 & 0,61 & 0,49 & 0,48 & 0,53 & 0,79 & 0,77 & 0,48 & \\
$\mathbf{F e}^{3+}$ & $-0,16$ & 0,09 & $-0,18$ & $-0,11$ & $-0,04$ & $-0,31$ & $-0,18$ & 0,15 & 0,02 & $-0,12$ & 0,01 \\
\hline
\end{tabular}

$\mathrm{O}$ pH não apresentou correlação significativa com a condutividade, pois, as interações água-rocha nos aquíferos da área urbana não promoveram processos hidrogeoquímicos que disponibilizassem maior quantidade de íons controladores do $\mathrm{pH}$, como exemplo: bicarbonatos, cálcio e magnésio. As demais correlações do $\mathrm{pH}$ com outros parâmetros também não foram significativas, indicando que não houve variação do $\mathrm{pH}$ causada pela presença dos íons dissolvidos das águas subterrâneas na área urbana de Lençóis. Significativas correlações também foram observadas entre cloreto e sulfato $(\mathrm{r}=0,93)$, cloreto e nitrato $(\mathrm{r}=0,72)$, cloreto e sódio $(\mathrm{r}=0,74)$, sulfato e nitrato $(\mathrm{r}=0,81)$, sulfato e fosfato $(\mathrm{r}=0,81)$ e sulfato e cálcio $(\mathrm{r}=0,89)$.

Nas rochas metassedimentares do Grupo Chapada Diamantina não há a ocorrência de minerais que possuem $\mathrm{SO}_{4}^{2-}, \mathrm{Cl}^{-}$ $, \mathrm{NO}_{3}{ }^{-}, \mathrm{PO}_{4}^{3-}$ ou $\mathrm{Ca}^{2+}$, sendo esperadas, dessa forma, baixas concentrações destes íons a partir da interação água-rocha, como foi possível observar nos resultados aqui apresentados. As exceções, foram as concentrações iônicas nos pontos P2, P3, P5 e P6, e que, de acordo com os coeficientes de correlação, pode-se afirmar, que as origens de tais íons são das mesmas fontes antrópicas.

As águas subterrâneas na área urbana de Lençóis, de acordo com a modelagem hidrogeoquímica, realizada pelo software Phreeqc, são predominantemente insaturadas em fases minerais formadas pelos íons que apresentaram maior atividade iônica nestas águas $\left(\mathrm{Cl}^{-}, \mathrm{Na}^{2+}, \mathrm{N}^{-\mathrm{NO}_{3}}{ }^{-}, \mathrm{SO}_{4}^{2-}\right)$. A exceção se dá pelas águas com concentrações significativas do cátion ferro $(\mathrm{P} 2, \mathrm{P} 7, \mathrm{P} 9, \mathrm{P} 11$ e P15) que se apresentaram supersaturadas nas fases minerais goethita $(\mathrm{FeOOH})$ e hematita $\left(\mathrm{Fe}_{2} \mathrm{O}_{3}\right)$. De forma geral, as espécies químicas predominantes nas águas subterrâneas do Grupo Chapada Diamantina (aquífero fissural, semi-confinado) são o $\mathrm{Cl}^{-}$e o $\mathrm{Na}^{2+}$. Nas águas das coberturas detríticas (aquífero granular, livre), além das espécies $\mathrm{Cl}^{-} \mathrm{e} \mathrm{Na}^{2+}$, predominam também as espécies $\mathrm{HCO}_{3}{ }^{-} \mathrm{e}$ $\mathrm{Fe}(\mathrm{OH})_{3}$.

As características delineadas para descrição dos fatores controladores da hidrogeoquímica e qualidade das águas, sugerem que estas águas podem estar condicionadas pela hidrólise. Este é o provável processo geogênico, de intemperismo dos minerais quartzo e feldspato contidos nas rochas e solos, que disponibilizam os íons para as águas subterrâneas na área urbana de Lençóis. Acrescido a este processo natural, há comprovadamente, a mobilização de íons de fonte antropogênica para a zona saturada dos aquíferos metassedimentares do Grupo Chapada Diamantina.

\section{CONCLUSÕES}

Com os resultados obtidos, pode-se concluir que, as águas subterrâneas na área urbana de Lençóis são doces, ácidas, moles, 
predominantemente límpidas e de baixa salinidade. Estas águas são do tipo cloretada sódica, ressaltando que, em um período de alta pluviosidade, esta tipologia poderá mudar em função da mobilização de determinados cátions e ânions para a zona saturada dos aquíferos. Maiores concentrações de nitrato observadas nas águas subterrâneas em alguns pontos da área urbana indicam contaminação por águas residuárias.

Nas rochas do Grupo Chapada Diamantina não ocorrem minerais constituídos por cloreto, sulfato, fosfato e cálcio, e em alguns pontos de uma zona da área urbana, as águas subterrâneas apresentaram maiores concentrações destes íons. Estes íons, mostraram uma forte correlação com o nitrato, reforçando a hipótese de contaminação das águas subterrâneas em uma zona da área urbana por fontes antropogênicas. $\mathrm{O}$ íon ferro apresentou maiores concentrações em dois pontos do aquífero metassedimentar, resultante da oxidação dos revestimentos dos poços e nos três do aquífero granular através da mobilização dos íons das crostas lateríticas.

O diagrama de Gibbs, a especiação química e os testes estatísticos de correlação, sugerem que a interação água-rocha pouco contribui na disponibilização de íons para as águas subterrâneas na área urbana de Lençóis, sendo resguardada características de águas do domínio da precipitação (baixa concentração de sais dissolvidos). Além disso, as fontes geogênicas dos poucos íons dissolvidos nas águas podem ser atribuídas ao processo de hidrólise, que ocorre entre a água e os minerais de quartzo, constituintes das rochas na região.

De forma geral, as águas subterrâneas da área urbana de Lençóis apresentam uma boa qualidade ambiental, necessitando de poucos ajustes para usos. São águas de classe especial, I e III pela resolução CONAMA 396/2008. Estão aptas para usos primários e secundários, desde que estejam em conformidade com os parâmetros micróbiológicos. Os níveis de contaminação das águas de uma zona da área urbana de Lençóis ainda são baixos, entretanto, os gestores municipais devem estar atentos, realizar monitoramentos e executar ações que cessem a mobilização destes contaminantes antrópicos para os aquíferos.

A cidade de Lençóis, tem o turismo como principal atividade econômica, e as águas subterrâneas na área urbana são essenciais para suprir as demandas exigidas por esta atividade. Neste cenário, é necessário a adoção de um plano diretor municipal que contemple ações de controle das águas urbanas e esgotos; delimitação de áreas de proteção; zoneamento da vulnerabilidade e dos riscos de contaminação dos aquíferos; além de educação ambiental e capacitação técnica dos atores que manejam este importante recurso natural para a cidade de Lençóis, em prol de garantir a exploração equilibrada, sem a deterioração da sua qualidade.

\section{AGRADECIMENTOS}

Os autores agradecem a CAPES, pelo financiamento do projeto de pesquisa. Ao Programa de Pós-Graduação em Geologia da UFBA e ao Núcleo de Bacia Hidrográfica da UESC, pelo suporte técnico e cientifico. A Associação de Condutores de Visitantes de Lençóis (ACVL) pelo apoio logístico. Aos hotéis, pousadas e seus respectivos proprietários pelo acesso aos poços. Aos avaliadores, pela importante contribuição, através de dicas e sugestões para o aperfeiçoamento cientifico deste artigo.

\section{REFERÊNCIAS}

APHA - American Public Health Association. Standard methods for the examination of water and wastewater. 22 th ed., Washington, 2012.

BRASIL. Conselho Nacional do Meio AmbienteCONAMA. Resolução 357, de 17 de março de 2005. Dispõe sobre a classificação dos corpos de água e diretrizes ambientais para o seu enquadramento, bem como estabelece as condições e padrões de lançamento de efluentes, e dá outras providências. Brasília: CONAM, 2005. 
BRASIL. Conselho Nacional do Meio Ambiente CONAMA. Resolução 396, de 3 de abril de 2008. Dispõe sobre a classificação e diretrizes ambientais para o enquadramento das águas subterrâneas, e dá outras providências. Brasília: CONAMA, 2008.

BRASIL. Ministério da Saúde. Portaria $\mathbf{n}^{\circ}$ 2914/MS, de 12 de dezembro de 2011. Dispõe sobre os procedimentos de controle e de vigilância da qualidade da água para consumo humano e seu padrão de potabilidade, e dá outras providências. Legislação. Brasília: MS, 2011.

CETESB - Companhia Ambiental do Estado de São Paulo. Decisão de Diretoria $n^{0}$ 195-2005. CETESB, São Paulo, 2005.

CONBOY, M.J.; GOSS, M.J. Natural Protection of Groundwater against bacteria of fecal origin. Journal of Contaminant Hydrology, v.43, p.124, 2000.

CONCEIÇÃO, F. T; MAZZINI, F; MORUZZI, R. B; NAVARRO, G. R. B. Influências Naturais e Antrópicas na Qualidade da Água Subterrânea de Poços de Abastecimento Público na Área Urbana de Marília (SP). Revista Brasileira de Recursos Hídricos, v. 19, n. 3, p. 227-238, 2014.

CPRM. Serviço Geológico do Brasil. Projeto cadastro de fontes de abastecimento por água subterrânea. diagnóstico do município de lençóis, estado da bahia. In: VIEIRA, A. T., MELO, F., LOPES, H. B. V., CAMPOS, J. C. V., GUIMARÃES, J. T., COSTA, J. M., BOMFIM, L. F. C., COUTO, P. A. A., BENVENUTTI, S. M. P. da (org.). Salvador, 2005, 22p.

CUSTÓDIO, E., LLAMAS, M. R. Hidrologia subterrânea. 2 ed. Barcelona: Omega, 1983, 2 v.

GIBBS, R.J. Mechanisms controlling world water chemistry. Science, v.17, p.1088-1090, 1970.

GOMES, O. V. O., AIRES, J. R., MARQUES, E. D., SILVA-FILHO, E. V. Análise da salinidade dos aquíferos na bacia do Macacu, Itaboraí, RJ. Águas Subterrâneas, v. 27, v. 2, p. 1-15, 2013.

ESRI. ArcGIS (Version 10). Los Ángeles, United States: Environmental Systems Research Institute, Inc. 2010.

ESTATCAMP., DIGUP. Action Stat. São Carlos-
SP, Brasil, 2016.

IBGE. Instituto Brasileiro de Geografia e Estatística. Cidades - Estimativas de população. $2016 . \quad$ Disponível em: <http://www.ibge.gov.br/home/estatistica/popula cao/estimativa2016/estimativa_tcu.shtm>. Acesso em: 17 de março de 2017.

KOPPEN, W. Climatologia con un estudio de los climas de la tierra (transl. P. R. H. Peres), Fondo de Cultura e Economica, Mexico City, Mexico, 1948.

LONG, D. T., LYONS, W. B., HINES, M. E. Influence of hydrogeology, microbiology and landscape history on the geochemistry of acid hypersaline waters, N.W. Victoria. Applied Geochemistry, n. 24, p. 285-296, 2009.

MATIATOS, I. Nitrate source identification in groundwater of multiple land-use areas by combining isotopes and multivariate statistical analysis: A case study of Asopos basin (Central Greece). Science of The Total Environment, v. 541, p. 802-814, 2016.

MATTOS, J. B., CRUZ, M. J. M., DE PAULA, F. C. F. Hidrogeoquímica das águas subterrâneas no município de Lençóis, Bahia, Brasil. Brazilian Journal of Aquatic Science and Technology, v.19, n. 2, p. 85-94, 2015.

MATTOS, J. B., DE PAULA, F. C. F. Análise geoambiental de uma microbacia hidrográfica no município de Lençóis, Chapada Diamantina (Bahia), Brasil. Sociedade \& Natureza, v. 29, n.1, p. 91-107, 2017.

MOBUS, G. Qualigraf. Programa para análise da qualidade de água. FUNCEME. 2014. Disponível em: <http://www.funceme.br/DEHID/index>. Acesso em: 10/09/2014.

MURGULET, D., TICK, G. R. Understanding the sources and fate of nitrate in a highly developed aquifer system. Journal of Contaminant Hydrology, v. 155, p. 69-81, 2013.

NASCIMENTO, S., SALES, C. A., RAIMUNDO, R. P. Diagnóstico hidrogeológico da região de Aramari e Ouriçangas-Bahia. Águas Subterrâneas, v. 29, n. 2, p. 146-161, 2015. 
NGUYEN, T. T., KAWAMURA, A., TONG, T. N., AMAGUCHI, H., NAKAGAWA, N., GILBUENA JR., R., BUI, D. D. Identification of spatio-seasonal hydrogeochemical characteristics of the unconfined groundwater in the Red River Delta, Vietnam. Applied Geochemistry, v. 63, p. 10-21, 2015.

OLIVEIRA, G. A., NASCIMENTO, E. L., ROSA, A. L. D., LAUTHARTTE, L. C., BASTOS, W. R., BARROS, C. G. D., CREMONESE, E. R., BENT, A. Q., MALM, O., GEORGIM, J., CORTI, A. M. Avaliação da qualidade da água subterrânea: Estudo de caso de Vilhena - RO. Águas Subterrâneas, v. 29, n. 2, p. 213-223, 2015.

PARKHURST, D. L.; APPELO, C. A. J. User's guide to PHREEQ C . A computer program for speciation, batch reaction, one-dimensional transport and inverse geochemical calculations. Denver: USGS, Water resources investigation Report 99-4259, 1999, 310 p.

PIPER, A. M. A graphic procedure in the geochemical interpretation of water-analyses. Transactions American Geophysical Union, v. 25, p. 914-928, 1944.

ROCKWARE INCORPORATED. RockWorks 16. Golden, CO, United States. 2015.

SAWYER, C. N.; McCARTY, P. L.; PARKIN, G. $F$. Chemistry for sanitary engineers. 4. ed. New York, McGraw-Hill, 2000.
SEI. Superintendência de Estudos Econômicos e Sociais da Bahia. Balanço hídrico do estado da Bahia. Salvador, 1999, 250 p.

SELVAKUMAR, S., CHANDRASEKAR, N., KUMAR, G. Hydrogeochemical characteristics and groundwater contamination in the rapid urban development areas of Coimbatore, India. Water Resources and Industry, v. 17, p. 26-33, 2017.

SILVA, R. C. A., ARAÚJO, T. M. Qualidade da água do manancial subterrâneo em áreas urbanas de Feira de Santana (BA). Ciência e Saúde Coletiva, v. 8, 4, p. 1019-1028, 2003.

SILVA-FILHO, E. V., BARCELLOS, R. G. S., EMBLANCH, C., BLAVOUX, B., SELLA, S. M., DANIEL, M., SIMLER, R., WASSERMAN, J. C. Groundwater chemical characterization of a Rio de Janeiro coastal aquifer, SE - Brazil. Journal of South American Earth Sciences, v. 27, n.1, p. 100-108, 2009.

VIVONA, R., PREZIOSI, E., MADÉ, B., GIULIANO, G. Occurrence of minor toxic elements in volcanic sedimentary aquifers: a case study in central Italy. Hydrogeology Journal, v. 15, p.1183-1196, 2007.

ZHANG, Q., SUN, J., LIU, J., HUANG, G., LU, C., ZHANG, Y. Driving mechanism and sources of groundwater nitrate contamination in the rapidly urbanized region of south China. Journal of Contaminant Hydrology, v.182, p. 221-230, 2015. 